\section{PLANEACIÓN \\ PARTICIPATIVA \\ INTERCULTURAL: \\ REFLEXIONES PARA EL \\ TRABAJO SOCIAL}

\section{Resumen}

Desde la década del noventa la planeación participativa surgió como estrategia vinculante para diversos sectores sociales, políticos, económicos y culturales que la dimensionaron como potencial de consenso en la construcción de procesos locales de mejoramiento social. Así mismo, fue legitimada como escenario para la praxis de profesionales formados en las ciencias sociales, principalmente en el Trabajo Social. Este artículo, desde una perspectiva geopolítica y geocultural, presenta elementos de contexto que determinaron la configuración de la planeación participativa en latinoamérica. Elementos que deben ser puestos en escena para replantear la diversidad y la perspectiva intercultural hacia la cual se ve abocada hoy esta estrategia movilizadora, ante la fuerza del discurso institucionalizado del desarrollo y por la emergencia de crisis y rupturas con este paradigma social desde otras prácticas y cosmovisiones de vida en los territorios.

Palabras claves: planeación, participación, interculturalidad

\section{Summary}

Since the nineties, participatory planning has emerged as a linking strategy for various social, political, economic and cultural sectors that assessed it as a potential for building consensus in the making of local processes for social improvement. Similarly, it was legitimized as a setting for practice for professionals trained in the social sciences, mainly Social Work. This article, from a geopolitical and geo-cultural perspective, presents contextual 
elements that determined the configuration of participatory planning in Latin America. These elements shall be staged in order to redefine diversity and the intercultural perspective that has been linked to this mobilizing strategy, against the institutionalized discourse of development and for the emergence of crisis and ruptures with this social paradigm from other practices and worldviews of life in the territories.

Key words: planning, participation, interculturality.

\section{INTRODUCCIÓN}

a planeación en latinoamérica surgió con el desarrollo en la posguerra, como medida para regular los asuntos de hacienda pública y para controlar el cambio social y cultural de la región mediante la institucionalización de una cierta racionalidad técnico instrumental sobre los recursos y las poblaciones que allí habitaban. Cómo objeto de la ciencia económica, la administración pública y el derecho, la planeación consistió en "una intervención del Estado dirigida a ordenar el desarrollo de la actividad económica y social, mediante la escogencia de un conjunto de alternativas para realizar los objetivos y las metas deseadas" (Calderón-Rivera, 1998: 24). Esta connotación implicó el privilegio de conocimiento científico basado en leyes económicas universales. Por su parte, la expansión de la planeación ocurrió por la imposición de organizaciones como el Banco Mundial, el Fondo Monetario Internacional y Las Naciones Unidas a través de la Comisión Económica para América Latina CEPAL, para otorgar la ayuda internacional y cuidar de los empréstitos en el marco de una agenda definida como Alianza de Ayuda para el Progreso de América Latina.

Este esfuerzo por racionalizar la inversión pública se afianzó durante las siguientes tres décadas con la intervención de los geógrafos y urbanistas, más específicamente por la incorporación de la cuestión territorial en la planeación del desarrollo, inicialmente referida al espacio e influenciada por la geografía alemana y sus modelos de economía regional urbana y la norteamericana con sus leyes de distribución espacial en las ciudades (Moncayo, 2001); y luego, como espacio territorial en el implicaba incorporar la tradición española de jurisdicción "descripción formal de los límites legales de un territorio" (Rinaudo, 2004: 29) conllevando así a un ordenamiento jurisdiccional del territorio bajo la consideración de que éstos se constituían en "ámbitos diferenciados de acumulación; es decir, la delimitación de los espacios de valoración de las burguesías nacionales, como territorios sobre los que se puede disponer de la dotación ambiental, la riqueza ya acumulada y la fuerza de trabajo" (Rinaudo, 2004: 44) y por lo tanto, se constituían en objetos de planeación.

Como planeación participativa, surgió en la década de los noventa en un contexto económico caracterizado por: primero los cambios en el sistema de acumulación de capital o de acumulación flexible basado en la capacidad innovadora, tecnológica y organizacional dependiente de "las políticas internas y las potencialidades propias, [para determinar...] sus posibilidades de desarrollo" (Moncayo-Jiménez, 2001:21) y segundo, en el marco de nuevas teorizaciones acerca de la gestión territorial en tanto, se consideraba que las decisiones cuya afectación eran para el desarrollo territorial dependían del mercado, el Estado y la sociedad civil, lo cual implicaba un fuerte consenso de intereses así como una forma diferente de orientar la configuración e intervención del Estado en instancias subnacionales.

Con la planeación participativa se generó a nivel político una racionalidad emancipatoria basada en los principios liberales de igualdad, soberanía y justicia redistributiva en donde las relaciones entre los sectores sociales, sus recursos y el territorio suponían una posible determinación sobre las particularidades del contexto local en materia económica, política y social, con lo cual se creaba la expectativa de una posible soberanía democrática aún en medio de un escenario neoliberal y globalizado.

Este ideario estuvo fuertemente determinado por el contexto geopolítico de la descentralización. La literatura de la década, particularmente la colombiana, especialmente la generada por el Consejo Nacional de Planeación en Colombia, apoyado en la Constitución Política de 1991, enfatizaba en la planeación participativa como planeación al derecho porque se consideraba que el ejercicio tecnocrático y centralista había sumido a la planeación en el desuso, por lo tanto, esta nueva planeación no tradicional la distinguía su carácter participativo y con ella se pretendía "no sólo racionalizar los planes de desarrollo, sino también incorporar a éstos la manifestación de una nueva racionalidad colectiva, construida en forma directa y participativa" (Forero Pineda, Cardona Moreno y Córdoba Martínez, 1999:3). Esta perspectiva compartida en gran parte de 
latinoamérica cifró en la planeación participativa el horizonte de protección de los derechos y una nueva reorganización territorial descentralizada a fin de proveer una mejor calidad de vida para los habitantes

Tras casi dos décadas de planeación participativa los análisis de las ciencias sociales han estado enmarcados fundamentalmente en su perspectiva política como asunto de gobernabilidad local y son escasos los estudios que indagan por otras facetas de la planeación participativa como estrategia movilizadora de las dos últimas décadas en la que se han involucrado amplios grupos de población, con la esperanza de mejorar, cambiar o consensuar frente a lo que debe ser el vivir en sus territorios.

Quizá la faceta cultural en los procesos de planeación participativa ha sido menos explorada ; no obstante, se advierte una intencionalidad expresa de incorporar la diversidad en la planeación participativa, lo cual ha generado la proliferación de planes étnicos, generacionales, de género y temáticos. En este contexto, este artículo tiene la intencionalidad de reflexionar acerca de esta inusitada fuerza de la diversidad en la planeación participativa y ampliar su debate introduciendo elementos que replantean o por lo menos complejizan el reconocimiento de esta diversidad, mucho más, cuando es promovida por la institucionalidad internacional del desarrollo como interculturalidad.

Desde una perspectiva geopolítica y geocultural y a partir de mi propia experiencia como activista social, profesional e investigadora en el tema de la planeación participativa, me propongo orientar esta reflexión hacia activistas, profesionales e investigadores de las ciencias sociales, especialmente de Trabajo Social porque considero que es conveniente poner en cuestión estas perspectivas predominantes de lo diverso y lo intercultural mucho más cuando se aplican en la configuración de una estrategia que busca ser emancipatoria como ocurre con la planeación participativa ${ }^{2}$.

1 En el caso colombiano, trochas ciudadanas o experiencias de planeación participativa local fueron representativas para orientar la gestión pública de los gobiernos municipales porque significaba"imaginar para poder encontrar un progresoy un desarrollo de su propia tierra, de su propio terruño, de su propia aldea y de su propio municipio"(Entrevista a Francisco Javier Restrepo, Consejo Nacional de Planeación, 1998: 40)

2 Me refiero a lo cultural en el proceso de planeación participativa que da cuenta de las relaciones, los imaginarios y los intereses que mueven las decisiones a nivel local, puesto que no es lo mismo que la planeación cultural.
Acorde a lo anterior, esta reflexión ubica en primer lugar el surgimiento de la planeación participativa en el escenario de la descentralización y las contradicciones inherentes en su práctica interna cuando la lucha cultural por el proyecto hegemónico local demarca su relación con el sistema económico globalizado. La segunda parte contempla las aspiraciones y las frustraciones que se tienen con la planeación participativa en su intención de configurar otros modos de desarrollo surgidos desde lo local porque relativizan la intencionalidad contrahegemónica al desarrollo universalizante y a la planeación hegemónica del Estado. Así mismo, se muestra como la lucha cultural interna toma otro matiz cuando se enfrenta con la representación y los dualismos establecidos entre lo moderno y no moderno, lo desarrollado y lo subdesarrollado. La tercera parte, recoge entonces la tensión de la diversidad y la interculturalidad en la planeación participativa cuando ésta emerge dentro del discurso del desarrollo como interculturalidad funcional y cuando es replanteada por la interculturalidad crítica en ruptura con el paradigma del desarrollo. Para cerrar y a grosso modo, identificaré algunos de los ámbitos que deben ser objeto de reflexión para las Ciencias Sociales y el Trabajo Social en su pretensión de transformación de las condiciones de vida o del vivir en territorios que aspiran a ser planeados participativamente en clave intercultural.

\section{La planeación participativa en el contexto latinoamericano de los noventa- siglo XX}

La planeación participativa surge en la década de los noventa en el escenario

La geopolítica es una ciencia que surge a fines del siglo XIX con los trabajos del politólogo sueco Johan Rudolf Kjellen (1864-1922) y del geógrafo alemán Friedrich Ratzel (1844 - 1904). Su objeto de estudio es la relación entre política de poder y geografía. Con los años y debido a las contribuciones de otras ciencias como la historia, la filosofía, la economía y las ciencias militares y de pensadores como Halford Mackinder, Kart Haushofer, Vidal de la Blache M. Illán, Milton Santos, Vivian Trías, Alberto Methol Ferré, Luiz Alberto Moniz Bandeira, entre otros, ha Milton Sanos, Vivios, ha complejizado el análisis de texto mundial.

La perspectiva de geopolítica que aborda este artículo es la de interacción entre lo geográfico, lo político y lo histórico en la configuración del poder entre grupos humanos y territorios en el contexto mundial del desarrollo.

En cuanto a geocultura, retomaré el sentido de Rodolfo Kusch muy bien sistematizado por Mauricio Langón (2005) en cuanto a que, lo geocultural hace referencia a un contexto geográfico fuertemente demarcado por lo cultural en el que el pensamiento de sus pobladores está condicionado por lo que se ha constituido como cultura del lugar. 
de la descentralización, marcado por demandas sociales de diversa índole y por el fenómeno del neoliberalismo. A nivel geopolítico, la participación emergió como la fórmula del consenso para configurar la vida local y a nivel geocultural fue la lucha cultural interna la que demarcó el acontecer del proyecto hegemónico local.

La descentralización fue promovida por la banca internacional (BM, BID y FMI) dentro de sus medidas de ajuste estructural. El Banco Mundial, por ejemplo, en sus estudios sobre América latina en 1999 enfatizaba en la transformación de la estructura del ejercicio de gobernar para la estabilidad política y la profundización de la democracia en la región latinoamericana, alegrándose que la región "ha puesto en marcha la transferencia del poder, recursos y responsabilidades hacia entidades subnacionales de gobierno" (Burki, Perry y Dillinge, 1999:1). Por su parte, el Fondo Monetario Internacional en sus revistas Finanzas y Desarrollo de los noventa, enfatizaba en la descentralización como apoyo a sus medidas de ajuste estructural para regular las economías y ajustarlas al nuevo cambio internacional. El Banco Interamericano de Desarrollo en su balance sobre la descentralización destacaba el cambio importante de la región en materia de regímenes democráticos

Uno de los argumentos más convincentes para la descentralización es la ventaja natural que los gobiernos locales y regionales poseen en relación con el gobierno central para lograr un buen balance entre los bienes públicos provistos por los gobiernos locales y las preferencias de la población (Lora, 2007: 248)

La descentralización fue elogiada y defendida también por la institucionalidad del desarrollo en América Latina. En las publicaciones de las Naciones UnidasCEPAL, a través del Instituto Latinoamericano y del Caribe de Planificación Económica y Social ILPES en su serie sobre gestión pública, se destacaba que en América Latina hasta la década de 1950 prevaleció la planificación central pero que a posteriori se planteaba necesario reducir el protagonismo de los gobiernos nacionales y descentralizar hacia los gobiernos locales muy acorde con la transformación productiva de la época. Por lo tanto y según Iván Finot (2001) frente al dilema entre desconcentración esto es -transferencia de competencias de decisión a organizaciones situadas por fuera del centro sin elección popular- y descentralización, solamente podría aceptarse esta última si se producía la transferencia de poder a nivel político, económico y administrativo. De esta manera, la descentralización de la gestión pública se refería básicamente

Al proceso de provisión de bienes públicos y por tanto no interesa cualquier privatización sino la referida a dicha provisión [puesto que] cualquier organización no estatal, sin distinguir entre organizaciones económicas y sociales, también pueden ser proveedoras de bienes públicos (p.39)

Signada por la geopolítica mundial, la descentralización fue promovida por diversos sectores económicos, sociales, políticos y culturales que pugnaban por el quiebre en la centralización política administrativa del Estado debido a su incidencia negativa en la dinámica económica y social a nivel nacional e internacional, de ahí que se promoviese el municipio como centralidad para la gestión pública' . En ella confluyeron las corrientes neoliberal y democratizante, aparentemente contradictorias, pero como se verá más adelante, inscritas en común en el mundo moderno capitalista. Como lo mencionara José Luis Coraggio (1991) el problema de la excesiva centralidad estatal generaba una acumulación de recursos económicos, funciones administrativas y poder social con limitantes no sólo para resolver los problemas sociales, sino también porque esta centralidad estatal ocurría respecto del poder legislativo y de los gobiernos provinciales conllevando a la frustración en las expectativas de desarrollo. La descentralización en según Coraggio (1991) vendría a modificar esta situación "mediante el trasvasamiento de recursos, atribuciones y poder en general, desde la cúspide del Estado hacia las bases del mismo Estado o bien hacia la sociedad" (p.2). Sin embargo, por la forma en que fueron condicionándose las políticas nacionales para acceder a los créditos o ayuda internacional esta descentralización en su versión neoliberal tendió a erosionar las bases de la autonomía puesto que bajo la nomenclatura de los principios de la libertad y escondió un proyecto de gigantesca centralización capitalista del poder económico a escala mundial ejecutado desde los Estados, apoyándose en las interpretaciones más centralistas del poder político; las mismas que se pretendería superar (p.6). De esta manera y siguiendo a este intelectual, los ejes administrativo y político cedieron ante el económico para posibilitar que

1 Para ampliar se puede consultar toda la serie de revistas Foro de la Fundación Foro Nacional por Colombia 
desde lo local se abriese a la competencia internacional bajo un supuesto de gobernabilidad como devolución de la soberanía a los ciudadanos.

La corriente democratizante por su parte, emergió según Coraggio (1991) "promoviendo sus propias acciones pero sobre todo disputando el sentido a las acciones de descentralización que promueven las fuerzas neoliberales" (p.9). En esta dirección, se impulsaba la propuesta de concentrar la descentralización en el eje político a fin reformular no sólo el Estado sino la sociedad política como un ejercicio de soberanía, en el que se combinase la democracia participativa con la representativa y se promoviese la autogestión entre el Estado- usuarios-trabajadores y otros agentes privados. Se trataba entonces de "aceptar la fuerza de la motivación por el interés particular, pero no en nombre de la ganancia, sino de la calidad de los servicios básicos recibidos y de la equidad en su distribución" (p.10).

Dentro de esta contradicción en la descentralización, la participación fue un marco común para lograr el consenso de los sectores sociales en la configuración de las dinámicas económicas, sociales y políticas propias de los territorios locales emergentes. El Banco Mundial en su informe (1999) enfatizaba en el capítulo III, sobre eficacia de ésta en el desarrollo ya que, era necesario "el reconocimiento de la importancia de la participación, las asociaciones y el capital social" (p.112) y anunciaba en su próximo informe sobre pobreza y desarrollo que la estrategia debería asegurar la potenciación de los pobres

Permitiendo que tengan más voz y participación en el proceso de adopción de decisiones [...]como un insumo vital para el mejoramiento de las políticas e instituciones, el eficaz suministro de servicios y el establecimiento de la base política necesaria para impulsar un crecimiento que favorezca a la población pobre(p.118)

Esta imposición se extendió como fórmula de consenso hacia una descentralización en la que democracia era un concepto y categoría plástica ajustable a múltiples intereses.

Fue así que, entre crecimiento económico, globalización, democracia y participación emergió la planeación participativa con serias contradicciones frente a lo que constituía el contexto local, sobredimensionado por aquel entonces gracias al bagaje literario de la época. El Banco Interamericano de
Desarrollo en su estudio "la alternativa local: descentralización y desarrollo económico" (De la Cruz, Pineda y Pöschl, 2010) dedica 21 capítulos a demostrar que gobiernos sólidos en contextos descentralizados y aprovechando las ventajas de las alianzas con el sector privado en un clima abierto de competitividad internacional podían logra el desarrollo local fomentando la productividad y mejorando la calidad de vida en sus territorios. Pero, desde la sociología del desarrollo surgían otras voces que insistían en que "no toda subdivisión de un territorio nacional es una sociedad local" (Arocena, 1995: 20) porque debían darse ciertas condiciones en lo socioeconómico y lo cultural referidas a las posibilidades de generar riqueza local que a su vez pudiese ser controlada mediante valores comunes y bienes localmente gestados.

Sin embargo, la identificación de lo local con lo político-administrativo y su reorganización, le bajó el perfil a la discusión económica. Sin descartar los esfuerzos que desde la economía social se hacían y se siguen haciendo por generar circuitos económicos locales a través de la pequeña empresa y la economía solidaria, el marcado énfasis en lo político favoreció que la economía neoliberal se naturalizara hacia una profunda fe en "la empresa como sistema de acción local" (Arocena, 2001) aspirando que estuviesen integradas en el entorno natural y social de la región y articuladas con los gobiernos y los consumidores desde una perspectiva de fomento de la acumulación flexible como la denominan los teóricos del desarrollo local' ${ }^{1}$. Por lo anterior, la planeación participativa parecía conducir a facilitar el enclave en la geopolítica mundial, tornándose así el ejercicio de la participación como máxima expresión de soberanía, todo ello bajo el supuesto del consenso local

Ahora bien en un contexto de globalización económica, la configuración de lo local, puso de manifiesto que el consenso de los diversos sectores sociales era a su vez una lucha cultural dualista de clases que pugnaban por la hegemonía del proyecto local. El tema cultural no fue objeto de reflexión explícita en la planeación participativa porque se presumía la existencia de una cultura local compacta en términos de valores y más bien mediada por asuntos de interés que serían resueltos con la participación y la existencia de gobiernos locales lo suficientemente sólidos. Esta noción de interés abordada desde la sociología de la cultura por Pierre Bourdieu y su economicismo, lo considera como una construcción histórica en donde la Illusio (palabra de origen latín) refiere al

1 Empleo cursiva para denotar conceptos o categorías de uso normal que son controvertibles. 
hecho de estar involucrado y reconocer que, lo que ocurre tiene implicaciones, ello implica, dominar las reglas del juego en donde convergen los intereses. Por lo tanto, cada participante ocupa un lugar diferente dentro de una relación binaria entre dominador y dominante. De esta forma, según él, existen tantos intereses como campos históricamente delimitados (Bordieu y Wacquant, 1995)

El contexto de globalización en el que se produjo la descentralización, animó aún más la lucha emancipatoria de los sectores populares y su movilización de las décadas anteriores. Como lo mencionaba el historiador José Luis Romero (1990) "desde fines del siglo XVIII la presencia de los sectores populares en la escena histórica es insoslayable" (p.5) versión que empleaba para cuestionar justamente una tradición histórica afincada en el estudio de las élites. De esta manera, lo que se produjo con la descentralización en el contexto de la globalización y que tuvo incidencia directa en la planeación participativa fue la lucha cultural interna expresada según José Luis Coraggio (1991:20) como

Una lucha cultural prolongada desde todos los niveles e instancias sociales y estatales accesibles, orientada hacia una hegemonía popular capaz de administrar democráticamente o de plantear alternativas para sobrellevar la crisis y a la vez ir perfilando formas alternativas de organizar la convivencia social

No obstante, esta lucha cultural por la hegemonía del proyecto local, planteada en su carácter dualista no es de fácil definición porque en primer lugar no se podía hablar de una única identidad popular puesto que, como lo menciona José Luis Romero (1990), una tendencia cree que esta identidad popular "recorre la historia, sustancialmente igual a sí misma, o al menos lo suficientemente resistente a los cambios como para que pueda identificarse la presencia de un sujeto en períodos o circunstancias muy diferente [...] impermeable a las fuerzas de los sectores dominantes" (p.6) y tampoco se puede afirmar que los sectores populares "carecen completamente de toda identidad propia; todo lo que son es lo que les han dicho que tiene que ser; todo lo que tienen es una variante degradada de la cultura de la élite, que a fuerza de vieja se ha hecho Folk"(p.6)

Así mismo, el criterio de clase dominante, ampliamente abordado por los estudios culturales latinoamericanos con Jesús Martín Barbero, Néstor García Canclini, Renato Ortiz, Jorge González, entre otros, aportaron y aportan a la comprensión de la denominada cultura popular en relación a los sectores populares y más específicamente cuando las actividades culturales cumplen funciones que se asumen con relación a la dominación social (Mattelart, Armand y Neveu, Eric, 2004). En este sentido, las élites según Néstor García Canclini (1995) llegan a ser clases hegemónicas:

En tanto incluyen en las instituciones, los objetos y mensajes, en su función y su sentido -además de sus intereses sectoriales - aquella parte de las culturas que los vuelve útiles y significativos para la mayoría (p.100)

Por contradicción, los sectores populares llegan a configurar la cultura popular como resultado de:

Una apropiación desigual de los bienes económicos y simbólicos existentes en una sociedad [...de la cual deriva] una elaboración propia de sus condiciones de vida [...] sentido cultural propio y luego, en la medida en que se toma conciencia de esta polaridad, de esta desigualdad [se genera] un enfrentamiento, una interacción conflictiva con los sectores hegemónicos (p. 62)

Pero el interés no es fácilmente clasificable por sector o clase porque "esa mezcla es lo propio de todo el proceso social y cultural: el conflicto, la coexistencia, la impureza" (Romero, 1990:6). Comprendido así, se complejiza aún más la lucha cultural interna en la planeación participativa debido a que, como lo mencionaba anteriormente, se privilegiaba la ubicación del interés en una clasificación por sectores (sociales, económicos, políticos, etc) y la clasificación de las poblaciones en virtud de su estrato socioeconómico. No obstante, el punto de encuentro en medio de la discusión sobre las contradicciones en lo local fue el fenómeno de la globalización, porque la descentralización jugaba un papel ambivalente, ante el cual, la planeación participativa retomaba fórmulas de la filosofía política como el interés común y la voluntad general, para intentar resolverlas.

Por lo anterior, se puede apreciar que la planeación participativa surge 
geopolítica y geoculturalmente determinada por las contradicciones que se generan en su interior como estrategia identificada para consolidar una propuesta emancipatoria que desde local pudiese interactuar adecuadamente con el mundo globalizado, interpretado de diversas maneras. La construcción entonces del proyecto hegemónico local planteó otra interpretación al dualismo de clases y a su coexistencia. Según Romero (1990:7) "los sectores populares son copartícipes de un único mundo social y cultural" y a su vez Canclini (1995:191) decía que "al tratarse de hegemonía y no de dominación, el vínculo entre las clases se apoya menos en la violencia que en el contrato, una alianza en la que hegemónicos y subalternos pactan prestaciones recíprocas" versión que puede ser discutida por la copresencia de consenso y la coerción como mecanismos para lograr la hegemonía, tal y como ocurre con los proyectos macro de desarrollo. De allí que, la lucha cultural en su carácter emancipatorio impuso la necesidad de configurar un sujeto de liberación, por eso, insisto en decir que al ocuparse la planeación participativa más de ubicar lo político como un asunto de gobernabilidad y menos como un asunto de la relación entre cultura y poder condujo a ocultar el plano de la representación y de los imaginarios que de forma latente configuraban el interés de los diversos sectores que allí convergían.

\section{Planeación participativa y desarrollo, ¿̇aspiraciones} contrahegemónicas?

Las contradicciones inherentes de la planeación participativa en su perspectiva emancipatoria son proyectadas en su intención de constituirse como estrategia contrahegemónica al desarrollo universalista y a la planeación centralizada y estatista. En este sentido, la lucha cultural interna marcada por el interés de clase o sector, se agudiza frente a las representaciones binarias establecidas por el sistema mundo capitalista moderno entre sociedad moderna y tradicional, desarrollada o subdesarrollada.

La planeación participativa emergió como alternativa contrahegemónica a la planeación y al desarrollo como se venían diseñando y aplicando. Contrahegemónica porque aspiraba una nueva visión del mundo y un cambio de dirección (Campione, 2009) en el cual las clases generalmente ignoradas o subalternizadas entrarían a hacer parte de todas las decisiones que afectasen sus vidas en el territorio que habitaban:

La planeación participativa al asumirse como proceso de diseño de futuros posibles que reconoce la especificidad y que parte de los contextos particulares donde la propia experiencia tiene lugar, no se aparta del sentido de construcción social del territorio específico. La preocupación por el territorio desde el horizonte de la planeación participativa va más allá de su ordenación son fines funcionales y físico espaciales, la preocupación de la planeación participativa por el territorio se centra en la expresión de la sociedad que aspira construir (Obando y Otros, 2003: 23)

Esta perspectiva contrahegemónica de la planeación participativa proyectada para lo local en el escenario de la descentralización se volvía "un campo abonado para la reconstrucción de modelos de desarrollo y democracia que consultan de manera directa las expectativas de los ciudadanos" (Obando y Otros, 2003: 39) bajo el supuesto de alcanzar así una mayor ingerencia en el bienestar, y la inclusión especialmente en las ciudades.

Sin embargo, las expectativas del desarrollo localmente gestionadas, se enfrentan ayer y hoy con la geopolítica del desarrollo que opera mediante un amplio marco discursivo reconfigurado y resignificado en sus enfoques, el cual, a través de las mediciones, coloca a las localidades en clara competencia con el marco global y universalizante de éste. El desarrollo y su matriz economicista continúan independiente de las adjetivaciones que adquiera el desarrollo. Los indicadores establecidos por el Banco Mundial, el Fondo Monetario Internacional, las Naciones Unidas y la CEPAL presentados en sus informes sobre desarrollo mundial y nacional a nivel humano, sostenible, socioeconómico, etc. El Banco Mundial por ejemplo cuenta con más de 800 indicadores para cada informe anual de 153 economías analizadas con sus 17 temas centrales y más 2000 indicadores cuando son disgregados. La CEPAL cuenta con más de 150 indicadores socioeconómicos y el Índice de Desarrollo Humano ha sido ampliado con otros indicadores como el de libertad humana (1991) redefinido en (1992) como libertad política, en (1993) se creó el índice de participación y en (1994) es planteado como desarrollo humano sostenible (1995), se propuso el índice de potenciación de la mujer IPM. Otros indicadores son el índice de pobreza por capacidad IPC (1996), el Índice de pobreza humana (1997) y desde 1998 se mantienen los tres componentes básicos del IDH: ingreso per cápita, esperanza de vida al nacer y escolaridad relacionados en cada temática de cada informe anual. Ahora bien, aunque son ampliamente generosos en número, 
Para los países, las ciudades y los territorios planeados participativamente se volvió imperativo superar la escala mundial en que habían sido ubicados. La medición se convierte en el instrumento para condicionar la ayuda y para definir las proyecciones del desarrollo. Cumplir con éstos imperativos se torna prioritario en la escala local debido al poder hegemónico de la institucionalidad generada con el desarrollo y sus discursos pero, además, el ideal de proponer modelos alternativos locales queda aplazado porque a la situación de economía dependiente se suman factores como la realización de ajustes macroeconómicos que conduzca a lograr mayor estabilidad macroeconómica para una mejor inserción en el mercado internacional y un crecimiento económico sostenible teniendo presente el alto nivel de concentración de poder económico en un sistema social basado fundamentalmente en la exclusión (Reyes,2007)

Pero a su vez, el sentido homogenizante y universalizante del desarrollo es cuestionado desde la planeación participativa por considerarse "ajenos a la cosmovisión de las sociedades específicas" (Obando y Otros, 2003: 15), se intentó controvertirle generando modelos propios de desarrollo que se convirtiesen en fuente de identidad frente a otros tipos de desarrollo. Aún así, la filosofía de vida que se homogeniza con los enfoques de desarrollo a través de sus informes, su aparato institucional y las políticas de ayuda, conllevaron a que las perspectivas de vida local y su bienestar, se ajustasen al discurso hegemónico, con ciertos matices como ocurre con la economía solidaria, pero ajustados a las lógicas de la geopolítica mundial.

En tal sentido, el peso de la relación intrínseca entre desarrollo y economía capitalista supone que "es el sistema mundo y no las distintas <<sociedades>>, lo que se ha venido desarrollando" (Wallerstein, 2004:129) y en esta vía, el desarrollo histórico del sistema capitalista ha supuesto la creación de los nacionalismos y de clases sociales y en sus expansiones sucesivas "de ser un sistema localizado primordialmente en Europa [a pasado] a otro que cubre la totalidad del planeta" (p.254). Igualmente, este sistema mundo que lleva más de 500 años ha requerido de centros de poder hegemónico, lo cual hace suponer que si antes fue Italia, luego Holanda, Inglaterra y actualmente Estados Unidos, esta hegemonía será transitoria también. Por lo tanto, lo local presenta un cierto nivel de movilidad interna, pero finalmente debe insertarse en la lógica del mercado transnacional o desaparece. En este sentido, menciona
Wallerstein (2004):

Es inútil analizar los procesos de desarrollo social de nuestras múltiples sociedades (nacionales) como si fueses estructuras autónomas, de evolución interna, cuando en realidad fueron y son ante todo estructuras creadas por procesos a escala mundial y como reacción frente a ellos (p.131).

La lucha cultural interna por su parte, parece encontrar una fórmula de mediación en la búsqueda de identidad "la que emerge y se consolida en las cotidianidades comunitarias y sociales en cada interacción comunicativa y participativa con ellos y frente a los otros" (Obando y otros, 2003:16). Los estudios culturales han debatido ampliamente el tema de la identidad especialmente por la importancia que reviste desde muchos sectores sociales el afincarse en ella frente a la globalización y los riesgos de fragmentación que puede implicar para las sociedades. En este sentido, es pertinente advertir que este intento de esencializar y unificar la cultura local apelando a la identidad invisibiliza que la identidad es un concepto "estratégico y posicional" (Hall,1996: 17) porque se configura de múltiples maneras y con posiciones contrarias y antagónicas. El asunto pertinente entonces, no es quienes somos sino "como nos han representado y cómo atañe ello al modo como podríamos representarnos" (Hall, 1996:18), es decir, cómo nos hemos construido como sujetos y sociedades en nuestras relaciones históricas. En esta dirección, la lucha cultural interna ya existente por el control de los recursos, se agudiza en términos de cuáles han de ser los valores culturales predominantes. Así, la relación entre cultura y poder se hace explícita en el desarrollo porque indica cómo y bajo qué estándares se debe vivir. Su hegemonía se afianza culturalmente:

En la producción de un modo de vida - en el que las prácticas vinculadas a la producción económica ocupan un lugar clave - donde las prácticas habituales, íntimamente ligadas a lo que llamamos cultura, inscritas en la misma textura de la experiencia cotidiana, van a producir efectos decisivos sobre la manera en que esa sociedad percibe y reproduce una visión del mundo, de los objetos, de los hombres y de la historia (Alapín y Mariano, 1998: 2) 
De allí que las interpretaciones que se hacen desde el desarrollo acerca de lo que constituye el pasado y el futuro de las sociedades lleva implícita una intención civilizadora. La pugna entre lo que se considera valores tradicionales y modernos, comportamientos apropiados y no apropiados, lo correcto y lo incorrecto hacen que los discursos del desarrollo sean igualmente normativos. Los aportes de la sociología con Norbet Elías $(1987 ; 1989)$ acerca del proceso civilizatorio que se gesta en las sociedades occidentales aporta algunos elementos que a nivel cultural son claves como por ejemplo la diferenciación progresiva que se pretende gestar con el cambio de los vínculos entre los individuos y sus sociedades; la separación entre lo que constituye lo íntimo y lo público y el cambio progresivo que se pretende dar al uso de la fuerza y el sentido de la política y de la economía entre muchos otros aspectos. Lo que interesa destacar acá, es que la lucha cultural en lo local se complejiza aún más en términos de la presión geocultural que se impone a nivel mundial, lucha de la cual participan todos los sectores sociales que conforman el escenario local. Así, los sistemas de creencias, la música, la oralidad, los símbolos, los objetos y los tipos de relacionamiento entran en contradicción con lo considerado válido en materia de producción intelectual, artística, sistemas filosóficos, organización de la vida social, política y económica y, la propia condición de la vida humana en el territorio que se habita.

\section{La planeación participativa en clave intercultural}

Con la incorporación de la diversidad y el diálogo intercultural en el discurso institucionalizado del desarrollo, la planeación participativa se ve impulsada a incorporarla en su connotación de derecho. Esta interculturalidad funcional es cuestionada desde la corriente mundial antidesarrollista y es revisada desde la interculturalidad crítica. La importancia de este debate radica en los replanteamientos que conllevaría direccionar la planeación participativa en perspectiva intercultural. Para las Ciencias Sociales y el Trabajo Social se hace oportuno retomar estas discusiones porque son replanteamientos a los ideales emancipatorios con los cuales abordamos las relaciones con los grupos humanos y sus territorios de vida y confiamos en estos procesos de planeación participativa.

La diversidad cultural, siempre existente en los pueblos del mundo, paso de ser problema para el desarrollo a estrategia potenciadora de éste. La perspectiva actual de las Naciones Unidas (2004) como organismo institucional del desarrollo, acerca de la diversidad es referida a "opciones, que tienen que ver con el reconocimiento y la acogida de diversas etnias, religiones, idiomas y valores y fueron, por mucho tiempo, consideradas amenazas para la armonía social, constituyen un elemento ineludible del panorama político del siglo XXI"

(p.1). Esta visión es compartida por su filial la Unesco (2001) que la define como: pluralidad de las identidades que caracterizan a los grupos y las sociedades que componen la humanidad que requiere una interacción armoniosa, inseparable del contexto democrático y como factor de desarrollo la diversidad constituye elecciones no solamente en términos de crecimiento económico, sino también como medio de acceso a una existencia intelectual, afectiva, moral y espiritual satisfactoria" (p.1)

Pero no siempre fue así, porque las diversas manifestaciones de la cultura local fueron ubicadas en la década del cincuenta del siglo XX como problemas del desarrollo. Los informes de las comisiones de expertos daban cuenta de ello, por eso, la modernización se convirtió en la estrategia para inducir al desarrollo y superar lo identificado como atraso'. En la década del noventa, la lucha de los movimientos sociales generó replanteamientos hacia este modo de concebir el desarrollo. El movimiento feminista contribuyó en gran medida para que se abriese el panorama de la diversidad más allá del criterio de clase, con su perspectiva primero de inclusión de las mujeres y luego del género tanto como los movimientos ecologistas, juveniles, entre otros. En el 2000 contribuyeron también los movimientos religiosos del mundo, las luchas étnicas, la situación de los migrantes en los países del norte procedentes del sur y del bloque exsocialista cuyas reivindicaciones hacen parte de la agenda internacional. Las Naciones Unidas (2004) recogen este panorama mundial y lo analizan desde la perspectiva liberal como libertad cultural ${ }^{2}$. Para tal fin, se hace un reconocimiento de la diferencia y se sitúa la diversidad como derecho. Las naciones son instadas a orientar políticas multiculturales y las manifestaciones de grupos religiosos, étnicos y migrantes son ubicadas, en su expresión extrema, como dominación cultural, asunto al deben estar atentos los gobiernos y tomar las medidas restrictivas del caso.

1 Sugiero consultar la recopilación de Decsi Arévalo Hernández (1997)

2 Construida desde el siglo XVIII por pensadores como Turgot, Gibbson, Smith, Condorcet, Godwin, Malthus, Kant y Spencer entre otros, como parte de un evolucionismo social en el que se avisoraba el crecimiento económico y la ciencia como baluartes de progreso, visión consolidada con el economicismo del siglo XX. 
Desde la perspectiva anterior el reconocimiento de la diversidad es puesta en escena por los organismos internacionales como estrategia para superar los problemas de exclusión de minorías preferiblemente, necesitadas de integración debido a las ausencias de desarrollo y lo que ello conlleva:

La ideología, discriminación, pobreza y desigualdad, liderazgo manipulador, estados débiles o ineficaces, intervenciones políticas externas, vínculos con diásporas hostiles. Aquellas instancias donde el desarrollo y la gobernabilidad fracasan dejan un vacío que los movimientos coercitivos no vacilan en llenar. (P.76)

Ahora bien, tanto las Naciones Unidas (2004) como su filial la Unesco (2009) culminan sus informes presentando las oportunidades que el mundo globalizado tiene para la diversidad cultural. Por ejemplo, en el Informe sobre libertad cultural (2004) la situación de exclusión de los pueblos indígenas, especialmente de sus conocimientos y por la extracción minera; la libre circulación de bienes culturales y; la situación de los migrantes, sugiere solucionarla con políticas multiculturales teniendo en cuenta que la defensa extrema de la tradición puede "frenar el desarrollo humano" (p.89) por ello, la defensa de la libertad cultural es según esta organización la defensa de las elecciones y finalmente, si bien se muestra importante la identidad local o nacional, el ideal debe ser constituirse como ciudadanos del mundo. La libertad cultural sirve entonces para reconocer la diversidad especialmente de estas minorías-pobres y hacer de ésta una oportunidad para compartir beneficios. El diálogo intercultural se considera posible según la Unesco (2009) "con un análisis de las diversas formas en que las culturas se relacionan unas con otras, la sensibilización a los elementos culturales comunes y las metas compartidas, y la determinación de los problemas que se deben resolver al conciliar las diferencias culturales"( p.9) Sugiere, como ciudadanos del mundo, superar el analfabetismo cultural, desarrollar competencias interculturales con la educación y desarrollar la inteligencia cultural en las empresas, es decir juntar cultura y economía.

La diversidad como derecho se vuelve así una directriz para la planeación participativa y si ésta se avizoraba como asunto de intereses y sectores sociales, ahora las categorías de calidad de vida, bienestar y nivel de vida al parecer, deben ser reinterpretadas. Sin embargo, la difícil comprensión de lo que significa planear en términos de diversidad ha generado la elaboración de planes (indígenas, afros, juveniles, ambientales, educativos y culturales entre otros) que afianzan una perspectiva multiculturalista de la sociedad y quizá promueven una interculturalidad funcional al sistema capitalista moderno.

Desde la corriente decolonial en latinoamérica, el reconocimiento de la diversidad, tal y como acontece, conlleva a una interculturalidad funcional porque mantiene vigente la representación de los casi dos tercios de la población del mundo como subdesarrollada o en vía de desarrollo; conservando intacta esta imagen y reproduciéndola' . Esta interculturalidad según los decoloniales, reconoce la diversidad para afianzarla en sus rótulos o estereotipos al emplear constantemente la categoría de minorías y al asociarlas con la pobreza por eso se impone administrar la cultura. Desde esta perspectiva, la diversidad como lo menciona Claudia Briones (2005) se convierte en un problema de gobernabilidad en que la acción positiva va aparejada con un nuevo fundamentalismo destinado a promover la democracia global. Esta suerte de "reparación histórica" (p.6) convierte la interculturalidad en un propósito para integrar a los indígenas, a los inmigrantes y despolitizar la cultura aduciendo fundamentalismos religiosos, étnicos o de otra índole. Esta interculturalidad es concebida como funcional porque "no cuestiona las reglas del juego y es perfectamente compatible con la lógica del modelo neoliberal existente" (Walsh, 2009:105) al situarla como un asunto de maximización de la libertad en el libre mercado del comercio de los bienes culturales.

La construcción de una perspectiva de interculturalidad crítica se fundamenta en el replanteamiento que se hace del sistema económico capitalista, su relación intrínseca con la ciencia y la imposición de concepciones y ritmos de la vida modernos a nivel planetario que con el desarrollo, mantienen vigente su colonialidad más allá de la descolonización².

1 Esta corriente ha sido impulsada desde la década del noventa por activistas sociales e intelectuales de latinoamérica como Enrique Dussel, Walter Mignolo, Santiago Castro, Edgardo Lander, Ramón Grosfoguel, Arturo Escobar, Catherine Walsh, Fernando Coronill y Aníbal Quijano, entre muchos otros. La decolonialidad es definida por Catherine Walsh (2005) como un proyecto de "desligadura conceptual" con la colonialidad del poder en la economía, la política, la vida íntima, el conocimiento para imponer un conocimiento único y totalitario. Sugiere entonces el pensamiento crítico para rompercon"las bases de la experiencia históricay subjetiva delaco articular un pensamiento de ruptura, el pensamiento crítico de-colonial" (p. 9)

2 La descolonización se considera el proceso independentista por medio del cual la presencia física del colonizar cesa. 
En este sentido, la obra de Inmanuel Wallerstein, los volúmenes en que analiza el sistema mundo moderno capitalista $(1979 ; 1984 ; 1998)$ y particularmente el texto Capitalismo histórico y movimientos antisistémicos (2004) recoge y pone a prueba lo que el denomina la capacidad que el sistema mundo ha tenido para hacer presente y futuro. Pero en esta vía, dice que las soluciones empleadas por el capitalismo han provocado cambios en la estructura subyacente y con el tiempo han ido royendo su capacidad para hacer los constantes ajustes necesarios "sólo afirmo [dice] que en medio de constantes aplausos a la eficiencia de la civilización capitalista, vemos por todas partes indicios de malestar y pesimismo cultural" (p. 131)

Nos encontramos entonces con una serie de expresiones en contravía de lo que se promueve con el desarrollo hegemónico. Encontramos por ejemplo la recuperación de semillas y prácticas de cultivo para resolver los impactos de la expropiación de tierras y para protegerse de los impactos transgénicos en seis provincias de Ecuador Imbabura, Pichincha, Cotopaxi, Tungurahua, Chimborazo y Bolívar de chocho, mashwa, oca, melloco, jícama, miso, quinua, zanahoria blanca promovidas por población campesina, indígena y afrodescendiente. Así mismo, la recuperación del cultivo de maíz en México en más de cien variedades, Recuperación de las variedades nativas de fríjol como tumbeño, patojito y liberal, y cinco nuevas variedades mejoradas de fríjol como: sangretoro, cargamanto rojo, bala, guarzo rojo y mediavara; variedades nativas de maíz como: yunga y diente caballo promovidas por campesinos del norte del Cauca (Grupo semillas, 1999). Encontramos los cultivos de agricultura urbana en diversos lugares de latinoamérica. También el empleo de materiales no tóxicos para la construcción de vivienda con tierra apisonada como se hace en México. Prácticas sanativas por parte de yerbateros, sobanderos y rezanderos en las que se emplean hierbas aromáticas, cantos y símbolos para acompañar los rituales como el Temazcal.

Frente al dinero por ejemplo, el trueke de productos considerado por John Jairo Cano uno de sus activistas como "estamos escribiendo trueke con $\mathrm{k}$, porque estamos diciendo que son nuevas las cosas que estamos diciendo, que uno es el trueke ancestral, la cosa por la cosa, aquello por aquello, pero que hoy con nuestros saberes, con nuestras posibilidades, con nuestras necesidades, entonces habría que ser un poco más creativo (Gómez y Otros, 2009:197) y el intercambio de saberes prácticos que no están mediados por el pago en dinero sino por la reciprocidad son experiencias que se conjugan con los rituales religiosos en los que se expresa la diversidad, como por ejemplo, las prácticas religiosas afrobrasileiras, para mostrar su incidencia en toda la vida espiritual y social de quienes las practican, entre el estigma, la violencia y las estrategias defensivas (Cristiana Tramonte, 2001). Así mismo las festividades que recrean los mitos fundacionales o simplemente permiten mantener la cohesión de las comunidades y la educación con un sentido del conocimiento y aprendizaje para la vida práctica se realiza en ruptura con la institucionalidad educativa como medida para recomponer los saberes perdidos en el formato occidental, por ejemplo los nidos de lengua en más de 10 comunidades de Oaxaca-México que son un ejemplo de educación no bilingüe sino intercultural con la incorporación de lo mítico como parte del aprendizaje, estas y muchas otras prácticas de vida resisten entre contradicciones con las lógicas del capitalismo y la modernidad.

Estas prácticas encaminadas a la regeneración cultural de los ámbitos de comunidad como lo denomina Gustavo Esteva (1996) han sido destruidos con el desarrollo, por eso "regenerando su propia capacidad curativa [...] regenerar la tierra y la cultura y con el tiempo mejorar la nutrición [...] la recuperación de la propia definición de necesidad" (pp.70-71)denominadas por él mismo (2010) "La insurrección en curso", no depende de dirigentes visibles, retorna a los sentidos básicos de la vida como el comer, sanar, aprender, desde diferentes formas de relacionamiento entre el campo, la ciudad y la ciudad misma y a través de otras alianzas que en conjunto y "anticipan la forma de la sociedad por venir" (p.33)

En igual forma, se ha configurado desde la década de 1980 una corriente mundial antidesarrollista conformada por intelectuales de diversas partes del mundo como Arturo Escobar, Wolfgang Sachs, Vandana Shiva, Majid Rahnema, Jean Robert e Iván Illich, entre otros, cuya contribución ha sido la construcción de una crítica arqueológica al desarrollo en su carácter geopolítico y sus categorías naturalizadas en el discurso y práctica del desarrollo como Tercer mundo, subdesarrollado, pobreza, necesidades, progreso, planificación, producción, ayuda, entre otras, con la finalidad de mostrar como el desarrollo ha sido un sistema de representación que como campo discursivo se ha instaurado como certeza en el imaginario social con unas formas de conocimiento, un sistema de poder que regula su práctica y formas de subjetividad fomentadas con el discurso que hacen a las personas reconocerse como desarrolladas o 
subdesarrolladas (Escobar, 1999: 35- 43).

La crítica al desarrollo en su faceta cultural se refiere a la naturalización lograda de asuntos que hacen parte de cualquier proceso de desarrollo y que son retomados por la planeación participativa como inevitables:

1- El desarrollo de la posguerra recoge el ideal de progreso del siglo XIX frente a la importancia de lo económico y ésta perspectiva en el siglo XX según (Esteva, 1996) "se empobreció aún más en más en las manos de sus primeros promotores, que lo redujeron a crecimiento económico" (p.59) olvidándose de entrada del problema de la distribución. La corriente del decrecimiento desafía este supuesto y alerta frente a los excesos del mercado en su afán de acumulación porque genera desplazamientos masivos, exclusiones, consumismo y a nivel ambiental causa enormes daños al equilibrio ecológico de la tierra y la importancia de revertir la centralidad que el crecimiento económico ha tenido en la vida social ${ }^{1}$. Propone el decrecimiento para contrarrestar el crecimiento ilimitado. Básicamente es "renunciar al imaginario económico, es decir, a la creencia de que más es igual a mejor [recuperar...] el principio de simplicidad voluntaria [...] no es el crecimiento negativo [...] y sólo puede ser posible en una sociedad de decrecimiento. Esto supone una organización absolutamente diferente, en la que se replantea el lugar central del trabajo en nuestra vida" (Latouche, 2004: 69-72) y de la economía que ha sido maximizada y absolutizada con el desarrollo como única salida para el bienestar.

2- La imposición del método científico para conocer y dictaminar lo que ocurre en un territorio es cuestionado por la corriente de la poscolonialidad y la decolonialidad en latinoamérica, en dos sentidos ${ }^{2}$ : primero por la producción

1 El concepto de decrecimiento nace durante los años 1970 en parte a través de la tesis de Nicholas Georgescu-Roegeb como conciencia de las consecuencias atribuidas al productivismo de la sociedad industrial. El decrecimiento comienza a tomar gran fuerza en Francia durante los años noventa, cuandointelectualescomoSerge Latouche,VincentCheynety Francois Scheider denuncian el fracaso del crecimiento en lo ambiental, la salud y la agudización de la pobreza y, crítica la paradoja de la acumulación porque justifica la desigualdad.

2 La poscolonialidad es una corriente de intelectuales como Edward Said, Homi Bhabba, Gayatri Spivak, Ranajit Guha y Samir Amín, entre otros que han puesto en evidencia la reproducción de la visión creada en Europa sobre los colonizados por parte de los intelectuales que tras las independenciashancontinuadoreproduciendoestos patrones deconocimientoyderepresentación. Enel caso Indio han sido relevantes los aportes de Guha y Spivak para cuestionar la historiografía por continuar el colonialismo británico con la cual se crea la falsa idea de un nacionalismo unificado de un tipo de conocimiento científico en el que se basa la producción de verdad y relega otras formas de conocer a la condición de pensamiento mítico no verificable y segundo por afianzarse a su vez, este conocimiento científico única y exclusivamente como producción de las sociedades supuestamente desarrolladas, generándose así un eurocentrismo epistémico. El africano Samir Amín (1989) dice que el eurocentrismo es un culturalismo que se presenta como un universalismo que propone la imitación del modelo occidental como única solución y es una dimensión de la cultura y la ideología del mundo capitalista. El peruano Aníbal Quijano (2003) enfatiza que el eurocentrismo es:

Una perspectiva de conocimiento cuya elaboración sistemática comenzó en Europa Occidental antes de mediados del siglo XVII [...] su constitución ocurrió asociada a la específica secularización burguesa del pensamiento europeo y a las necesidades del patrón mundial de poder capitalista, colonial/moderno, eurocentrado, establecido a partir de América" ( $p$. 218).

La incidencia entonces, está en términos del despojo de saberes que son transformados por la ciencia para luego determinar la toma de decisiones que se generan sobre el vivir porque privilegian unos modos de vida sobre otros.

3- La imposición del cambio a tiempos y espacios mediados únicamente por la razón moderna cuya característica es la vida de prisa, sobredimensiona la capacidad humana y técnica como únicas fuentes de poder y decisión para transformar la vida social para el desarrollo. De esta forma, el supuesto reflexivo en que se sustenta la modernidad queda soslayado porque según Robin Hissong (1991) "con los avances de la ciencia y la tecnología, y con la consolidación de la racionalidad burguesa en torno a la acumulación y valorización del capital, la noción de moderno tiene una connotación mucho más material que reflexiva" (p.15). Con el desarrollo y la imposición de metas sobre problemas agudizados por él mismo mediante proyectos que pretenden desde una lógica racional sobreponerse a los tiempos históricos, mucho más cuando ese tiempo se concibe en ruptura con el pasado como signo de atraso, promueven el desarraigo de cualquier vínculo con el lugar como lo ancestral y tradicional por una nueva espacialidad creada para el desarrollo en la que se privilegia la ciudad (difundido en los informes de hábitat de las Naciones Unidas) y; la reconfiguración espacial de lo rural como lugar de producción y no

creado por las élites en donde desaparece de escena el pueblo como tal. 
como ámbito de vida.

Estas imposiciones sobre cómo se debe vivir tienden a homogenizar la vida bajo el supuesto de lo considerado necesario. Paulatinamente, se va configurando un determinado tipo de humano, unas formas válidas de gobernar, un tipo de relacionamiento entre humanos y naturaleza e inclusive una forma de asumir los comportamientos religiosos o ética protestante.

En síntesis, el auge de la corriente antidesarrollista internacional y sus expresiones en los movimientos sociales antisistémicos en latinoamérica ubican la geopolítica y la geocultura mundial en otro escenario histórico, político, epistémico y ontológico desde el cual el desarrollo es criticado como paradigma homogenizante, instalado como dispositivo de poder del capitalismo, afianzado en el eurocentrismo como base y cimiento de la ciencia y la tecnología moderna, en el que el sujeto moderno actúa desde una supuesta libertad para escoger el tipo y modo de vida que desea cuando en realidad ha sido negado y construido desde esta perspectiva colonizadora.

La planeación participativa en clave intercultural requiere así, además de hacer visible su nexo con la interculturalidad funcional, incorporar la crítica cultural y los supuestos que sustentan la interculturalidad crítica decolonial como estrategia conceptual y política para develar las lógicas de poder que operan en el mantenimiento de esa colonialidad histórica y para visibilizar otros poderes, epistemes y seres en la perspectiva de un diálogo intercultural no asimétrico. En tal sentido, se alerta sobre cuestiones como:

A. La construcción que se hiciera de los pueblos colonizados ubicándolos como prehistoria en la historia universal construida por y desde Europa la cual como lo mencionan los poscolonialistas, sobrevive a la transferencia de poder que se genera con las independencias como neocolonialismo. Este nacionalismo de élite construye a su vez una historiografía de élite en la que las contribuciones de los pueblos indígenas, afrodescendiente y mujeres, entre otras, son invisibilizadas o visibilizadas en razón de los próceres. En tal sentido, esta historia de élite se promueve como valor cultural predominante.

B. Las asimetrías, ampliamente abordadas por la corriente de la filosofía intercultural, que se reproducen en igual mediad desde afuera e internamente para "la construcción de tradiciones, de su organización institucional o en las reglamentación de sus prácticas de vida" (Fornet, 2003: 20). mediante mecanismos como la cultura de museo y piezas intocables, el sentido que se le transfiere como dominante cuando son construcciones sociopolíticas de clases altas que las institucionalizan; la creación de bloques culturales para promover la interacción en la globalización, perdiendo de vista la necesaria construcción de un presente y futuro común en el que la cultura no debe constituir una reserva exótica sino una "diversidad de mundos reales con culturas históricamente activas" (p.26)

C. La competencia cultural que se establece abiertamente bajo el supuesto de libertad cultural y que conlleva al despojo de saberes y de territorios en virtud de poner a competir las poblaciones por su inserción en el mercado, quizá lo más perverso sea la planeación cultural para identificar otros polos de desarrollo en el contexto global.

D. La clasificación que se hace de los pueblos en razón de criterios raciales. Esta colonialidad del poder que sirvió de base para fundamentar el capitalismo con la conquista y la imposición del proyecto civilizatorio como mito fundacional de la versión eurocéntrica de la modernidad ó "idea del estado de naturaleza como punto de partida del curso civilizatorio cuya culminación es la civilización europea u occidental" (Quijano, 2003: 220). Se trata de un dualismo que inició como pagano/cristiano, salvaje/civilizado y continúa como desarrollado/ subdesarrollado, bajo el supuesto de la existencia de una cultura superior.

E. El asimilacionismo en las diversas formas que se promueven con la educación incluyendo la bilingüe en tanto se realiza un traslado de la estructura educativa y de la fundamentación pedagógica occidentalizada hacia la educación de pueblos que, reconocidos como diversos: indígenas, migrantes, afros, mujeres, etc; son educados en los principios y en las lógicas de la modernidad eurocéntrica.

F. La intención de reducir y cooptar otras cosmovisiones de vida que son conocidas hoy como el buen vivir, la comunalidad y el vivir bien como una variante más de la democracia occidental o del desarrollo en versiones como "otros desarrollos" o simples desarrollismos o economicismos en tanto que, se evalúa toda una historia ancestral por la participación que estén teniendo en los ámbitos constitucionales, ejecutivos y legislativos del poder estatal, 
como ocurre en Bolivia y Ecuador. Estas posturas reduccionistas opacan las posibilidades de discutir, comprender e interpretar estas experiencias como diálogos interculturales y ocultan el nivel de conflictividad que ello genera. Se traslada así, un problema que es de racionalidad y de la intelectualidad mestiza e indígena inclusive, hacia procesos que son históricos, ancestrales que han tenido la valentía de generar propuestas para superar la invisibilización ha que han sido sometidas durante siglos. Son muchas las premisas que generan debate como las citadas por el ministro de relaciones exteriores y cultos de Bolivia David Choquehuanca Céspedes (2007):

No buscamos vivir mejor simplemente buscamos un vivir bien; no buscamos una sociedad equilibrada [antropocéntrica] sino una vida equilibrada; la lucha va más allá de la libertad [...] buscamos una vida complementaria; tenemos que dejar de pensar solamente en los seres humanos [...] la energía comunal se desenvuelve en la cultura de la vida" (p.2)

La cuestión es si desde nuestra estructura cognitiva colonizada podemos interpretarlas adecuadamente.

\section{Para cerrar}

Como se ha podido apreciar, la planeación participativa se ve abocada a incorporar la diversidad cultural en sus múltiples expresiones. No obstante, la exclusividad de este reconocimiento para el reclamo como derecho, plantea el riesgo de la fragmentación social y la existencia de planes de todo tipo (educativos, culturales, ambientales, territoriales, etc) que poco dialogan entre sí con el riesgo en el olvido del proyecto social colectivo. Preguntarse por la representación que subyace en este reconocimiento es de vital importancia como lo es, que se amplíe el análisis geopolítico y geocultural en que ocurren las manifestaciones de la diversidad.

Para las Ciencias Sociales, específicamente el Trabajo Social, la promoción de la planeación participativa requiere ser replanteada en los siguientes términos:

1) Revisión del contexto geocultural en el emerge la diversidad cultural y su reconocimiento para identificar en dónde están las posibilidades de gestar propuestas antisistémicas. Ello requiere estar atentos al cercamiento de discurso del desarrollo cuando se promueve desde una condición política de la representación como subdesarrollado, puesto que, será contribuir a la reproducción del sistema mismo mediante la consolidación de élites, incluyendo profesionales y la continuidad en el despojamiento de los elementos comunes de la vida.

2) Replanteamiento epistémico acerca de cómo se configura y genera el conocimiento de los territorios y las poblaciones en relación a dos aspectos: el primero es el tipo de conocimiento que privilegiamos como válido y segundo, si bien es conveniente problematizar las condiciones de existencia, también es igualmente riesgoso ubicarlas única y exclusivamente desde la carencia puesto que se pierde de vista una serie de saberes y de estrategias de solución que invisibilizadas y subalternizadas se han conservado en el tiempo, pero pueden igualmente, constituirse en fuente de diálogo.

3) Es pertinente identificar las lógicas del poder que desde la geopolítica mundial se expresan, afianzan y contraponen en el escenario local que se planea participativamente; porque generalmente, los discursos que se promueven desde la institucionalidad del desarrollo, aparecen como de apertura, pero en la práctica cotidiana, cierran las posibilidades para soberanía local y más bien, es menester comprender que el desarrollo opera como paradigma y dispositivo de poder en un sistema mundial que deja ciertos márgenes para el intercambio cultural siempre y cuando esté en la lógica de la conservación hegemónica del capitalismo y los valores que le son afines en su reproducción.

4) Es conveniente replantear las bases conceptuales en que se sustenta el bienestar social, especialmente, porque una perspectiva de interculturalidad crítica, insta a cuestionar la noción de necesidad como carencia y de satisfacción con las disposición de dinero y a su vez, requiere replantear qué tan fructíferos son aquellos ejercicios de planeación participativa que conducen finalmente a equiparar la vida de un territorio con las estándares de vida universalizados, con lo cual se transforman en ejercicios costosos con difícil incidencia en política pública y con mucha responsabilidad por el desarraigo de sus gentes.

Lejos de intentar cerrar o reunir todas las aristas del debate acerca de la planeación participativa se abre un abanico muy importante de reflexiones, quizá la más determinante en estos momentos sea cómo posibilitar el diálogo 


\section{REFERENCIAS BIBLIOGRÁFICAS}

- Alapín, Helena y Mariano, Víctor. 1998. Algunas consideraciones sobre el concepto de Hegemonía. Recuperado el 6 de diciembre de 2009. Disponible en http://www.perio.unlp.edu.ar/problemas\%20sociologicos/ textos/de\%20la\%20catedra/HEGEMONIA.doc

- Arévalo-Hernández. 1997. Misiones económicas internacionales en Colombia. Revista HISTORIA CRITICA. Historia económica de Colombia. Diciembre, 14, Pág. 7-24

- Amín, Samir. 1989. El Eurocentrismo. Distrito federal, México: siglo XXI editores.

- Arocena, José.1995. El desarrollo local: un desafío contemporáneo. Uruguay, Montevideo: Universidad Católica de Uruguay, Centro Latinoamérica de Economía Humana (CLAEH), Editorial Nueva Sociedad.

- Arocena, José. 2001. El desarrollo local: un desafío contemporáneo. Uruguay, Montevideo: Taurus y Universidad Católica.

- Banco Mundial. 1999. Informe anual. Recuperado el 23 de julio de 2005, disponible en

- http://web.worldbank.org/WBSITE/EXTERNAL/BANCOMUNDIAL/QUIENE SSOMOS/0,,contentMDK:20193478 menuPK:60001941 pagePK:6405786 3 piPK:242674 theSitePK:263702,00.html

- Bordieu Pierre y Wacquant Löic J.D. 1995. Respuestas por una antropología reflexiva. México DF: Grijalbo.

- Briones, Claudia. 2005. La puesta en valor de la diversidad cultural: implicancias y efectos. Ponencia presentada en el encuentro sobre Etnoeducación, Multiculturalismo e Interculturalidad. Bogotá, Colombia.

- Calderón Rivera Camilo.1998. Planeación estatal y presupuesto público. Bogotá, Colombia: Editorial Legis.

- Campione, Daniel. 2009. Hegemonía y contrahegemonía en la Latinoamérica de hoy- Algunos apuntes hacia una nueva época. Recuperado el 18 de noviembre de 2009, disponible en http: //www.rebelion.org/docs/11306. pdf

- Consejo Nacional de Planeación. (1998). Trochas ciudadanas. Bogotá, Colombia.

- Coraggio, José Luis (1991). Las dos corrientes de la descentralización en
Latinoamérica. Cuadernos de CLAEH, № 56, 2a serie, 16, (1), 63-78.

- Choquehuanca-Céspedes, David. 2007. III Conferenza Nazionale ItaliaAmérica Latina e Caraibi. Roma, 16-17 ottobre. Consultado el 10 de noviembre de 2008, disponible en www.conferenzaitaliamericalatina.org/ es/conferenza.asp

- De la Cruz Rafael, Pineda Carlos y Pöschl Carolina. 2010. La alternativa local: descentralización y desarrollo económico: Banco Interamericano de Desarrollo.

- Escobar, Arturo. 1996. La invención del tercer mundo: construcción y deconstrucción del desarrollo. Santa fé de Bogotá, Colombia: Grupo editorial Norma.

- Elias, Norbert. 1987. la sociedad de los individuos. Ediciones península. Barcelona, España.

- Elías, Norbert, 1989. El proceso de la civilización: investigaciones sociogenéticas y psicogenéticas. Segunda Edición. México, DF. Fondo de Cultura Económica.

- Esteva, Gustavo. 1995. Desarrollo. En Wolfgang Sachs (Ed.) Diccionario del Desarrollo: una guía del conocimiento como poder (52-79 pp.). Lima. Perú: PRATEC

- Esteva, Gustavo. 2011. La insurrección en curso. Oaxaca, México: Documento digital sin editar.

- Finot, Iván. 2001. Descentralización en América Latina: teoría y práctica. Santiago de Chile: ILPES Naciones Unidas.

- Forero Pineda Clemente, Cardona Moreno Guillermo y Córdoba Martínez Carlos. 1999. Planeación participativa estrategia de paz. Bogotá, Colombia: Consejo Nacional de Planeación.

- Gómez Esperanza y Otros. 2009. Vivir frente al desarrollo: procesos de planeación participativa en Medellín. Colombia: Pregón Ltda.

- Fornet-Betancourt, Raúl. 2003. Culturas y poder: Interacción y asimetría entre las culturas en el contexto de la globalización. Bilbao, España: editorial Desclée de Brouwe. S.A.

- Hissong, Robin I. 1991. Las teorías y las prácticas de desarrollo desde la perspectiva de la modernidad. Bogotá, Colombia:Cider, Uniandes

- García-Canclini, Néstor. 1997. Ideología, cultura y poder. Buenos Aires, Argentina: Universidad de Buenos Aires.

- Grupo Semillas. 1999. Recuperación de semillas. No.13. Recuperado el 15 de octubre de 2011 Disponible en http://www.semillas.org.co/sitio. shtml?apc=p1-2--\&volver=1 
- Guha N.E. 1996. [1982]. Estudios subalternos. Traducción de Ana Rebeca Prada del artículo: "Preface". En: Subaltern Studies I. Writings on South Asian History and Sociely, Ranajit Guha, editor. Delhi: Oxford University Press.

- Hall, Stuart y Du Gay, Paul.2003. Cuestiones de identidad cultural. Buenos Aires, Argentina: Amorrortu editors.

- Javed Burki Shahid, Perry Guillermo E. y R. Dillinger William .1999. Más allá del centro, la descentralización del Estado. Washington, D.C: Banco Mundial. Disponible también en www.4shared.com/.../Banco_ Mundial_1999_Ms_all_de.html

- Langón, Mauricio. 2005. Geocultura. En: Salas Astrain, R. (dir.) Pensamiento Crítico Latinoamericano; Conceptos fundamentales. Santiago de Chile, U. Católica Silva Henríquez

- Latouche, Serge. 1996. Nivel de vida. En Sachs, Wolfgang. (Ed.) Diccionario del desarrollo: la guía del conocimiento como poder (1761939 pp.). Lima, Perú: PRATEC.

- Lora, Eduardo. 2007. El estado de las reformas al Estado en América Latina. Banco Interamericano de Desarrollo

- Moncayo-Jiménez, Edgar. 2001. Evolución de los paradigmas y modelos interpretativos del desarrollo territorial. Santiago de Chile: ILPES Naciones Unidas.

- NACIONES UNIDAS. 2004.Informe sobre desarrollo humano. Versión Digital, disponible en http://www.un.org/es/development/

- Obando, Álvaro y Otros. 2003. La planeación participativa una apuesta de ciudad. Corporación Región, Cedecis, Convivamos, IPC, Fundación Social. Medellín, Colombia: Pregón Ltda.

- Mattelart, Armand y Neveu, Eric. 2004. Introducción a los estudios culturales. Barcelona, España: Paidós.

- Quijano, Aníbal. 2003. Colonialidad del poder, eurocentrismo y Latinoamérica. En Lander, Edgardo La colonialidad del saber: eurocentrismo y ciencias sociales, perspectivas latinoamericanas (201246 pp.). Buenos Aires, Argentina: CLACSO.

- Reyes, E. Giovanni. 2007. Cuatro décadas en la historia económica de Latinoamérica. En REVISTA CAPÍTULOS DEL SELA, (60), 109-148

- Rinaudo R. Ulises. 2004. Gestión del desarrollo territorial. Bogotá Colombia: Universidad Piloto de Colombia.

- Romero, José Luis. 1990. Los sectores populares urbanos como sujetos históricos. REVISTA PROPOSICIONES. «Chile, historia y 'bajo pueblo'». Ediciones SUR, Santiago, (19) Pág. 268-278

- Swissaid.2011. Campaña Semillas. Recuperado el 14 de octubre de 2011. Disponible en http://www.swissaid.org.ec/ecuador/wEspanol/ ayudanos_a_ayudar/semillas.php

- Tramonte, Cristiana. 2001. Com a bandeira de Oxalá. Florianópolis, Brasil: Lunardelli

- Unesco. 2009. Invertir en la diversidad cultural y el diálogo intercultural. Informe mundial. Recuperado el 10 de febrero de 2010, disponible en http://unesdoc.unesco.org/images/0018/001847/184755S.pdf

- Unesco 2009. Declaración de los derechos culturales. Recuperado el 14 de septiembre de 2010. Disponible en http://unesdoc.unesco.org/ images/0012/001246/124687e.pdf\#page $=72$

- Wallerstein, Immanuel. 1979;1984;1998. El moderno sistema mundial. Madrid, España: siglo XXI

- Wallerstein, Immanuel. 2004. Capitalismo histórico y movimientos antisistémicos. Madrid, España: editorial AKAL

- Walsh Catherine. 2009. Desde...Abya Yala. Temas de interculturalidad crítica. Chiapas, México: Editorial Cidecis-Unitierra.

\section{Esperanza Gómez Hernández}

Trabajadora Social, especialista en gerencia del desarrollo social, magíster en investigación, gestión y desarrollo local y doctora en educación: Estudios interculturales. Docente/ investigadora asociada de la Universidad de Antioquia, facultad de Ciencias Sociales y Humanas, departamento de Trabajo Social. 